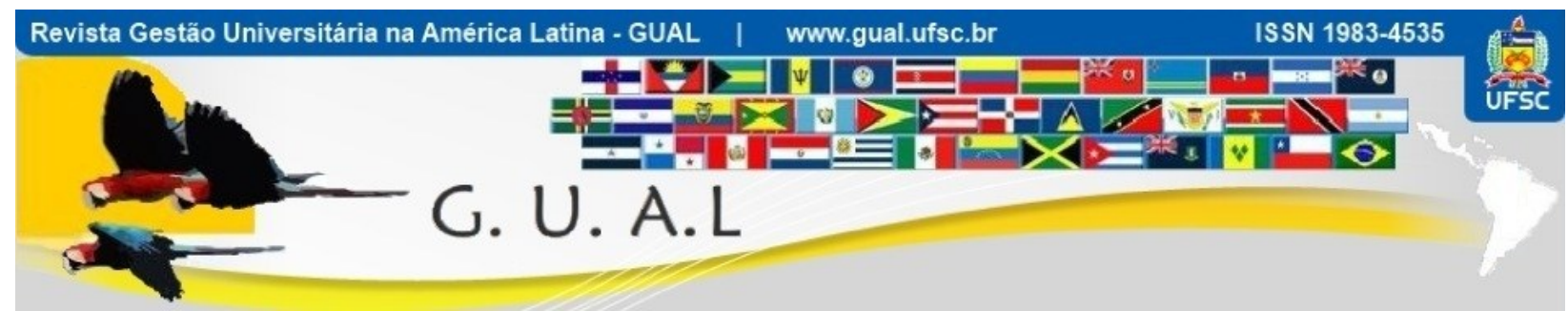

DOI: http://dx.doi.org/10.5007/1983-4535.2012v5n3p81

\title{
A CONTRIBUIÇÃO DO PDI NAS ATIVIDADES DE PLANEJAMENTO E GESTÃO DAS INSTITUIÇÕES DE EDUCAÇÃO SUPERIOR
}

\section{THE CONTRIBUTION OF PDI IN THE ACTIVITIES OF PLANNING AND MANAGEMENT OF INSTITUTIONS OF HIGHER EDUCATION}

Thiago Henrique Almino Francisco, Mestre Faculdade Capivari - FUCAP proftf@gmail.com

Marina Keiko Nakayama, Doutora Universidade Federal de Santa Catarina - UFSC marina@egc.ufsc.br

Alexandre Moraes Ramos, Doutor Universidade Federal de Santa Catarina - UFSC amr@cse.ufsc.br

Paulo Cristiano Oliveira, Mestre Universidade Federal de Santa Catarina - UFSC oliveirapco@yahoo.com.br

Recebido em 17/julho/2012

Aprovado em 27/novembro/2012

Sistema de Avaliação: Double Blind Review

Esta obra está sob uma Licença Creative Commons Atribuição-Uso. 


\title{
RESUMO
}

O artigo versa sobre os aspectos que confirmam a relevância do Plano de Desenvolvimento Institucional - PDI - na estruturação do planejamento e gestão das instituições de educação superior, apresentando aspectos que convalidam este fato nos diversos modelos institucionais vigentes na contemporaneidade nacional. A digressão teórica elenca aspectos relacionados às bases conceituais do planejamento universitário, a importância do Decreto 5773/06 na constituição do PDI, a contribuição dos documentos institucionais no processo de gestão e ao processo de planejamento nas instituições de educação superior, sob o lume do PDI como instrumento de destaque no cerne estratégico das instituições. Para tanto, as interações metodológicas ocorrem sob as bases da pesquisa acadêmica, de caráter documental indireto e que se classifica como sendo descritiva-explicativa, predominantemente qualitativa e designada como sendo uma pesquisa participante. As investigações construtivistas permitiram concluir, entre outros desígnios, que o Plano de Desenvolvimento Institucional é fator estruturante de uma gestão estratégica direcionada para a utilização de indicadores especificamente relacionados ao modelo institucional apregoado pela IES, além de contribuir na construção de um processo de avaliação institucional sistemático, formativo e determinante aos ensejos institucionais.

Palavras-chave: Planejamento. Educação superior. Plano de desenvolvimento institucional.

\begin{abstract}
The article focuses on aspects that confirm the relevance of the Institutional Development Plan - PDI - in structuring the planning and management of higher education institutions, with aspects that corroborate this fact in the various institutional models in contemporary society nationwide. The tour lists theoretical aspects related to the conceptual foundations of the university planning, the importance of Decree 5773/06 on the establishment of the PDI, the contribution of documents in the process of institutional management and planning process in institutions of higher education under the light of the IDP as an instrument of strategic focus at the heart of the institutions. For this, the interactions occur under the methodological foundations of academic research, documentary character of indirect and that is classified as being descriptive-explanatory, largely qualitative and designated as a research participant. The constructivist research allowed to conclude, among other purposes, that the Institutional Development Plan is a structural factor in the strategic management directed to the use of indicators specifically related to the institutional model advocated by IES, and contribute in building an institutional assessment process systematically, formative and crucial to the institutional good points.
\end{abstract}

Keywords: Planning. Higher education. Institutional development plan. 


\section{A CONTRIBUIÇÃO DO PDI NAS ATIVIDADES DE PLANEJAMENTO E GESTÃO DAS INSTITUIÇÕES DE EDUCAÇÃO SUPERIOR \\ DOI: http://dx.doi.org/10.5007/1983-4535.2012v5n3p81}

\section{INTRODUÇÃO}

O chamado liberalismo da educação superior, ocorrido com o advento da promulgação da Lei de Diretrizes e Bases da Educação Nacional determinou uma gama de ações sistêmicas por parte das instituições de educação superior que promovessem, entre outros aspectos, a perenidade. Neste sentido, no decorrer dos anos de consolidação da Lei, surge o Plano Nacional da Educação que traz metas em caráter decenal para o ensino superior, culminando na promulgação do Decreto 3860/2001 que determina a instituição legal do Plano de Desenvolvimento Institucional.

O Documento, tal como ensejado pelo Decreto, pressupõe aspectos que concernem à efetividade institucional, sobretudo no momento em que determina a aderência significativa com os pressupostos de qualidade e planejamento das instituições. Desse modo, a educação superior brasileira passa a adentrar a ume escopo teórico metodológico no qual suas ações passam a ser balizadas por aspectos que levam em consideração o cenário conjuntural da educação superior, sobretudo no sentido de manter uma coerência com as metas do Plano Nacional da Educação.

Com o surgimento da Lei 10.861/04 e, consequentemente, da Portaria 300/06, o PDI ganha status de referencial norteador da qualidade institucional, tornando-se instrumento fundamental na consolidação dos processos de avaliação institucional. Desse modo, confirmase o exposto por SINAES (2009) que destaca a contribuição fundamental do documento na construção do projeto de avaliação da instituição, o qual deve se manter aderente às premissas propostas pelo PDI.

Nesta conjectura, buscando a consolidação do PDI como um documento norteador dos processos de planejamento e gestão institucional, surge o Decreto 5773/06 que determina uma nova estrutura designada ao Plano de Desenvolvimento Institucional. A partir deste momento, o Documento passa a contar com o valor agregado dos pontos relevantes do Projeto Pedagógico Institucional, além de consolidar os objetivos institucionais, a área de atuação acadêmica e um retrato sistemático de sua epistemologia.

A promulgação da Portaria 40, em dezembro de 2007, traz a luz alguns aspectos que consolidam a estrutura sistêmica do PDI, consolidados na Portaria Normativa 23 de dezembro de 2010, ensejando das instituições um estudo significativo da sua estrutura operacional, a qual qualifica a gestão com base nos documentos institucionais. O Plano de Desenvolvimento Institucional passa a se consolidar como um documento dinâmico e flexível, mas que 


\section{A CONTRIBUIÇÃO DO PDI NAS ATIVIDADES DE PLANEJAMENTO E GESTÃO DAS INSTITUIÇÕES DE EDUCAÇÃO SUPERIOR \\ DOI: http://dx.doi.org/10.5007/1983-4535.2012v5n3p81}

determina um posicionamento concreto da instituição de educação superior a partir de pressupostos vinculados a competitividade.

A partir do surgimento do Índice Geral de Cursos, por intermédio da Portaria Normativa 12 de 5 de setembro de 2008, o PDI passa a se consolidar como um documento dinâmico e sistêmico no cerne institucional, já que passa a sofrer influencia de indicadores que devem constituir a identidade e a orientação qualitativa da instituição. Isso se confirma com os aspectos delineados pela Portaria 821 de agosto de 2009, alterando a composição do Conceito Preliminar de Curso que da base para a constituição do IGC, determinando um minucioso estudo estratégico na instituição e que configure ações planejadas no sentido de consolidar a qualidade e o posicionamento estrutural da instituição.

Nesta perspectiva, o PDI passa a ser considerado um documento estruturante do processo de planejamento institucional, desencadeando oportunidades de estudos sistemáticos no sentido de promover uma compreensão do escopo institucional a partir de ações concretas. Entre outros aspectos, pode-se afirmar que o Plano de Desenvolvimento Institucional passa a ser considerando um instrumento norteador das práticas institucionais e da avaliação institucional, permitindo a compreensão do posicionamento da instituição em um ambiente altamente competitivo, tal como se identifica na contemporaneidade.

\section{BASES CONCEITUAIS DO PLANEJAMENTO UNIVERSITÁRIO}

A educação superior, em suas bases epistemológicas, pressupõe uma contribuição das instituições no sentido de compreender o entorno a partir de uma visão a frente de seu tempo. As contribuições de Buarque (1994) consolidam este aspecto e evidenciam o papel das instituições que atuam de modo a contribuir com a qualidade de vida e os ensejos sociais. Para tanto, estas entidades, com fins lucrativos ou não, devem se apoiar em um processo de aprendizagem perene, sob as bases da proposta de Senge (1998), as quais convergem para resultados significativos na formação humana e social.

Nas bases da proposta constitucional brasileira, especificamente em seu Art. 207, propõe a contribuição do setor privado na consolidação de uma proposta de educação superior, ensejando, entre outros aspectos, a democratização do ensino, o acesso e a permanência. A Lei de Diretrizes e Bases - Lei 9394/96 - foi promulgada no sentido de consolidar as idéias de uma proposta coerente com o cenário identificado no Brasil, contribuindo, tal como evidencia Amaral (2006) para o desenvolvimento da economia e a 


\section{A CONTRIBUIÇÃO DO PDI NAS ATIVIDADES DE PLANEJAMENTO E GESTÃO DAS INSTITUIÇÕES DE EDUCAÇÃO SUPERIOR \\ DOI: http://dx.doi.org/10.5007/1983-4535.2012v5n3p81}

construção de uma nova sociedade a partir da formação de agentes capacitados à transformação social.

A partir da orientação da LDB, ocorre o que Garcia (2006) e Kleber e Trivisan (2010) classificam como o liberalismo da educação superior, onde as ações expansionistas, especificamente desencadeadas pelo setor privado, determinam uma expansão significativa das instituições de ensino superior. Neste cabedal, o boom da educação superior também tem respaldo na contribuição da proposta de Bolonha, inserindo este segmento num contexto de posicionamento, requerendo ações gerenciais, destacadas por Salles (2007), como fator preponderante à competitividade. Dessa forma, Tovolí, Segatto e Nogueira (2005) destaca que a educação superior, com fulcro nas bases legais e no direcionamento estrutural, deve propor ações visem contribuir de modo significativo para a emergência do mercado de trabalho e da sociedade, a partir de uma expansão quanti-qualitativa da educação superior e promovendo uma troca de experiências entre as instituições, inserindo-as em um cenário onde a contribuição do estado passa a ser fundamental.

Nesta conjectura, o processo de planejamento estratégico passa a ser fundamental para a consolidação dos objetivos institucionais, especificamente vinculados as tendências que o segmento deve enfrentar. Este aspecto, destacado por Lerner (1999), converge para uma contribuição que consolida o papel da educação superior, ensejando práticas que contribuem à para um melhor posicionamento de seus programas institucionais, atingindo seus objetivos designados no Plano de Desenvolvimento Institucional. Destarte, isso permite uma "nova estruturação interna para que haja condições de medições mais precisas e individuais e para que possa haver gestão dirigida (MACHADO 2008; p. 19)."

O planejamento, dentro deste contexto, consubstancia o processo reflexivo na instituição, destacado por Lerner (1999) como sendo substantivos na construção da identidade institucional ensejada por Brasil (2004) e por SINAES (2009). Na observância destes aspectos, Salles (2007) salienta a construção de uma abordagem sistêmica, transformado a instituição de educação superior em um mecanismo articulista de processos e recursos sociais para a consecução dos resultados institucionais, corroborando a contribuição de Silva (2008) e consolidando um processo eficiente de gestão institucional.

A gestão eficiente de uma Instituição de Ensino Superior - IES é de grande complexidade. A criação de valor para alunos, professores, funcionários e sociedade está fundamentada no gerenciamento equilibrado dos ativos intangíveis (conhecimento, processos, sistemas e informação) e no 


\section{A CONTRIBUIÇÃO DO PDI NAS ATIVIDADES DE PLANEJAMENTO E GESTÃO DAS \\ INSTITUIÇÕES DE EDUCAÇÃO SUPERIOR \\ DOI: http://dx.doi.org/10.5007/1983-4535.2012v5n3p81}

planejamento e controle dos recursos financeiros que se traduzirão na prestação de serviços educacionais e na perenidade financeira do negócio. (SILVA 2008; p. 16)

Entre outros aspectos, isso permite a compreensão, destacada por Hortale e Mora (2007), de funções institucionais que promovem a atratividade e a competitividade na instituição, aumentando, tal como evidencia Esteves (2007) a atratividade e a visibilidade institucional em vias de um posicionamento mercadológico. Consolida-se, por meio desta compreensão, uma sistemática direcionada a maximização de oportunidades na educação superior "não apenas sobre seus objetivos e funções, mas também no que se refere à sua estrutura, organização e administração, assim como sobre a eficiência e qualidade do seu trabalho, seus serviços, e a maneira como vem empregando os recursos oriundos da sociedade (ESTRADA 2000, p.32)".

O planejamento nas instituições de educação superior se consolida, portanto, na perspectiva traçada por Bertoldi (2006), onde os principais elementos a serem considerados no processo de orientação estratégica pautada na missão e visão, nas questões estratégicas, nas metas institucionais, na avaliação e no aprendizado.

A missão e a visão estão estritamente relacionadas às questões estratégicas da instituição, sobretudo no sentido de consolidar a identidade institucional designada por Brasil (2004), as quais servem de base para o estabelecimento de metas e objetivos que se consolidam nos procedimentos de avaliação institucional a partir da contribuição do SINAES. Por meio desta direção, tendo o respaldo dos instrumentos legais, surge um instrumento legal que direciona o posicionamento institucional, aglutinando valores que convergem para a orientação proposta pela Lei 10.861/04. Destarte, o Decreto 5773/06 surge para buscar a consolidação de um novo modelo de educação superior proposto para o Brasil.

\subsection{O PROCESSO DE PLANEJAMENTO NAS INSTITUIÇÕES DE EDUCAÇÃO SUPERIOR}

A perspectiva contemporânea da educação superior no Brasil requer uma significativa atenção aos aspetos sistemáticos do planejamento estratégico. Dentro deste novo contexto, Machado (2008) preconiza a necessidade da reflexão sobre um modelo de gestão estratégica aplicada às instituições, em virtude dos problemas atuais enfrentados e, sobretudo, em função de um novo posicionamento designado em função da competitividade que determina uma gestão profissional. 


\section{A CONTRIBUIÇÃO DO PDI NAS ATIVIDADES DE PLANEJAMENTO E GESTÃO DAS INSTITUIÇÕES DE EDUCAÇÃO SUPERIOR \\ DOI: http://dx.doi.org/10.5007/1983-4535.2012v5n3p81}

A educação superior, sobretudo na contemporaneidade brasileira, apresenta uma significativa representatividade, movimentando, conforma os dados apresentados por Esteves (2007), algo aproximado a R\$ 27 bilhões no mercado nacional. Neste contexto, grandes grupos educacionais passam a desencadear ações em função da consolidação de um novo mercado, estruturando processos de fusão e aquisição no sentido de prospectar e posicionar uma nova perspectiva para o segmento no Brasil. Esta, por sua vez, coaduna-se com a filosofia dos modelos educacionais vigentes, sejam eles públicos ou privados, estruturando um novo pensamento gerencial que requer práticas de planejamento imbricadas no pensamento gerencial, destacado por Voos (2004), como sendo essencial à consolidação dos objetivos acadêmicos e administrativo destas instituições.

O processo de planejamento, tal como evidenciado por Silva (2008), considera a importância de um modelo de gestão com base no Plano de Desenvolvimento Institucional, tendo-o como suporte para a construção de indicadores e a utilização de sistemas de apoio a decisão. Neste caso, o PDI orienta as ações institucionais que determinam a consolidação da identidade institucional proposta por Brasil (2004), determinando habilidades institucionais para promover uma resposta rápida aos ensejos do segmento da educação superior no Brasil, com ênfase em aspectos quantitativos e qualitativos.

Dentro desta conjuntura, Braga (2009) ainda contribui, ao apresentar uma análise do cenário educacional brasileiro e sua projeção para os anos seguintes, na qual pode-se inferir que os aspectos estruturantes do Plano de Desenvolvimento Institucional - PDI - passam a ser norteadores de práticas acadêmicas e administrativas que proporcionam pressupostos de desenvolvimento estrutural da instituição. Entre outros aspectos, isso permite uma compreensão significativa do mercado, contribuindo em práticas de prospecção de cenários e coadunando as ações de ensino, pesquisa e extensão.

Com base nas reflexões sobre o Planejamento no ensino superior, é consonante a necessidade de construir e estudar os indicadores os indicadores evidenciados por cada modelo e que posicionem a instituição no cenário e neste novo ambiente no plano da educação superior. Por este aspecto, Braga (2005) apresenta fatores determinantes para a qualificação de uma instituição de ensino superior, onde a complexidade do ambiente requer um novo pensamento administrativo, destacando a contribuição de toda a comunidade acadêmica na estruturação do processo reflexivo. Em uma projeção para o futuro, as principais qualificações que posicionarão as práticas institucionais de uma IES estão 


\section{A CONTRIBUIÇÃO DO PDI NAS ATIVIDADES DE PLANEJAMENTO E GESTÃO DAS INSTITUIÇÕES DE EDUCAÇÃO SUPERIOR \\ DOI: http://dx.doi.org/10.5007/1983-4535.2012v5n3p81}

relacionadas, entre outros aspectos, ao nível do aluno ingressante, a metodologia de ensino/aprendizagem e aos mecanismos de controle do processo de aprendizagem, além de processos de controle acadêmico e gerencial, especificamente aplicados em cada modelo.

A linha de pensamento apresentada por Esteves (2007) segue a preposição de Porter (1990), destacando a competitividade que urge com a evolução do segmento do ensino superior no Brasil, destacando o posicionamento de forças competitivas que arrolam novas práticas determinantes ao posicionamento de todas as instituições. A partir de um estudo destas inferências, pode-se conceber, entre outros aspectos, os dados da demanda, da oferta, dos diferenciais competitivos e que direcionam a utilização de modelos de posicionamento direcionados a estrutura reflexiva da instituição.

Já nas contribuições de Marcelino (2004), o planejamento se confirma a partir da constituição de gestão estratégica sob a égide de indicadores, corroborado pela visão de Silva (2008). Desse modo, ao Implantar um modelo de gestão em uma instituição de ensino superior deve ensejar qualificação dos sujeitos envolvidos no processo de gestão, criando e consolidando oportunidades de análise do mercado como um todo e, dessa forma, disseminar as práticas acadêmicas que sustentem os valores pregados pela instituição, posicionando sua marca no mercado.

Isso se confirma em virtude da relevância de uma análise de cenário e do desenvolvimento de modelos de gestão aplicado às IES, os quais determinam uma nova estrutura organizacional para o ensino superior e a confirmação de pressupostos gerenciais designados por Steiner e Malnic (2006). Contudo, em função do comportamento gerencial dos responsáveis por esta sistemática nas instituições, identificam-se casos tais como destacados na contribuição que segue:

Segundo a mentalidade de mantenedores e dirigentes ainda é pouco afeita aos avanços da "ciência da gestão", uma vez que, diferentemente de outros setores da economia, boa parcela dos dirigentes educacionais não teve formação em gestão e nem a prática mercadológica que seus cargos a exige. Terceiro, as tarefas rotineiras e operacionais do dia-a-dia de uma instituição de ensino costumam ser tão envolventes que os gestores educacionais ocupam quase todo o seu tempo "apagando incêndios" ou cumprindo rituais burocráticos, restando pouquíssimo tempo para planejar o futuro da empresa. (BRAGA, 2005; p. 11)

E conforme Machado (2008) antes da aplicação de modelos de gestão estratégica nas instituições deve-se atentar para uma reestruturação interna, em função de uma complexidade 


\section{A CONTRIBUIÇÃO DO PDI NAS ATIVIDADES DE PLANEJAMENTO E GESTÃO DAS INSTITUIÇÕES DE EDUCAÇÃO SUPERIOR \\ DOI: http://dx.doi.org/10.5007/1983-4535.2012v5n3p81}

sistêmica no cenário acadêmico, considerado fatores críticos ao sucesso das práticas de gestão, os quais consolidam a utilização de indicadores específicos a cada modelo.

A partir dos aspectos imbricados no conceito do planejamento aplicado a educação superior, as inferências de Braga (2005) confirmam a necessidade da inserção das instituições no âmbito de modelos de gestão, já que as questões estratégicas que justificam a busca pela competitividade e a sobrevivência no mercado se posicionam de modo substantivo e determinam a perenidade das instituições. E desse modo, considerando a relevante participação dos gestores no processo, desenvolver práticas que obedeçam a sua identidade e seu mercado de atuação, o planejamento orientado para a contribuição estratégica do Plano de Desenvolvimento Institucional passa a ser fundamental.

\subsection{O DECRETO 5773/06 - UM NOVO MOMENTO DA EDUCAÇÃO SUPERIOR NO BRASIL}

A estruturação da educação superior no Brasil passa por um processo dinâmico e continuo, no sentido da busca constante de uma epistemologia designada aos seus diversos modelos. Com base nas contribuições de Brasil (1988), este segmento de ensino torna-se substantivo e determinante para a construção de uma sociedade justa, designando atividades intelectuais no contexto da formação do homem. Sousa (2007) destaca a contribuição do aprendizado fundamentado nas diversas reformas universitárias ocorridas ao longo do tempo, destacando o posicionamento da educação superior como veículo de transformação social.

Com o advento da nova LDB - Lei 9394/1996 - a educação superior no Brasil ganha sua forma contemporânea, designando funções que vão da contribuição publica e privada, destacando a educação como um dever da família, contribuindo para o chamado "liberalismo universitário". O Decreto 3860/01, construiu uma versão inicial deste retrato, contribuindo para determinar uma nova realidade no ensino superior brasileiro, o qual caminhava para a livre expansão, sobretudo por meio do segmento privado, onde a autorização, o reconhecimento e a renovação de reconhecimento dos cursos de graduação constituíam fator restritivo ao posicionamento estratégico das instituições.

$\mathrm{Na}$ acepção deste posicionamento, institui-se o Plano de Desenvolvimento Institucional, como sendo um instrumento norteador das ações institucionais, destacando por Bertoldi (2006) como um documento institucional de caráter estratégico e que permite construir um retrato quantitativo e qualitativo da instituição. Neste caso, o PDI promoveria a consolidação de uma estrutura organizacional, contendo o "histórico da IES, sua implantação 


\section{A CONTRIBUIÇÃO DO PDI NAS ATIVIDADES DE PLANEJAMENTO E GESTÃO DAS INSTITUIÇÕES DE EDUCAÇÃO SUPERIOR \\ DOI: http://dx.doi.org/10.5007/1983-4535.2012v5n3p81}

e evolução, descrição atual com dados quantitativos e qualitativos, estrutura organizacional e de gestão, objetivos e metas que pretende realizar no ensino, na pesquisa e na extensão" (BERTOLDI 2006, p. 35).

Ao passo desta construção, contudo, havia de se considerar o Plano Nacional da Educação, evidenciado por Brasil (2001), que destacava, entre outros aspectos, metas inerentes ao ensino superior para o decano 2001- 2011. Entre seus diversos termos, o Documento destacava metas vinculadas a democratização, acesso e permanência, posicionando métodos para esta consecução, requerendo também a contribuição de um instrumento legislativo para sua consolidação. Nestes termos, em 09 de maio de 2006 surge o Decreto 5773, destacado por Frauches e Fagundes (2007) com um direcionamento para a consolidação de um modelo de educação superior diferenciado dos demais já desenvolvidos no cenário brasileiro.

No âmbito de seus principais objetivos, Frauches e Fagundes (2007) destacam uma contribuição significativa no sentido de promover a normatização das funções regulatórias, avaliativas e de supervisão da educação superior brasileira, instituindo uma sistemática de controle e desenvolvimento de cursos de graduação. É neste sentido que Rizzo (2009), faz menção de um novo posicionamento gerencial destas instituições, contribuindo para a consolidação de práticas que determinem uma nova esfera da educação superior no Brasil.

Do ponto de vista da gestão, a promulgação do decreto trouxe novas preocupações no cerne da educação superior brasileira, a qual estava em franca expansão e buscando consolidar métodos de democratização, acesso e permanência. Com base nas contribuições de Frauches e Fagundes (2007) o Decreto tinha, em suas principais funções, a meta de consolidar um sistema proposto às instituições do sistema federal de ensino, enquadrando os atos regulatórios de credenciamento, recredenciamento, reconhecimento e renovação de reconhecimento dos cursos de graduação.

As bases legais do decreto estão centradas, especificamente, em alguns instrumentos legais que direcionam as ações da educação no Brasil. Na Constituição Federal, o decreto traz os aspectos regulatórios designados à iniciativa privada, destacando o Art. 209, o fato de que "o ensino é livre à iniciativa privada, atendida as seguintes condições: I - cumprimento das normas gerais da educação nacional; II - autorização e avaliação da qualidade pelo Poder Publico" (BRASIL 1988). 


\section{A CONTRIBUIÇÃO DO PDI NAS ATIVIDADES DE PLANEJAMENTO E GESTÃO DAS INSTITUIÇÕES DE EDUCAÇÃO SUPERIOR \\ DOI: http://dx.doi.org/10.5007/1983-4535.2012v5n3p81}

Na Lei de Diretrizes e Bases da Educação Nacional - Brasil (1996) - apresenta o escopo direcionado à avaliação da qualidade, estabelecendo, entre outros aspectos, direcionamentos que consolidam a avaliação institucional nas bases de Brasil (2004). Dentro deste contexto, o Decreto procura também consolidar os processos administrativos no âmbito da administração institucional, utilizando-se para tal as bases de Brasil (1999), incitando práticas de regulamentação nas relações institucionais com administração publica federal e estabelecendo normas básicas e que resguardam os direitos dos agentes envolvidos.

Em linhas gerais, a consolidação do Decreto estrutura-se na contribuição da avaliação institucional e faz jus à utilização dos aspectos relacionados ao Sistema Nacional de Avaliação da Educação Superior, instituindo, designando documentos institucionais para a construção de uma identidade institucional significativa no segmento do ensino superior, onde se destacam o Projeto Político Institucional (PPI), os Projetos Pedagógicos de Curso (PPC) e, o mais importante, o Plano de Desenvolvimento Institucional (PDI). A Lei 10.861 de 14 de abril de 2004, neste contexto, traz à luz uma significativa preocupação com a gestão institucional e o controle, possibilitando a utilização de frameworks no contexto da gestão dos projetos institucionais e coaduna-se com as necessidades do modelo acadêmico atual, onde os documentos institucionais são fundamentais.

\subsubsection{A gestão pelos documentos institucionais}

A busca pela consolidação ensejada pelo Decreto 5773/06 trouxe um novo direcionamento no contexto gerencial e estratégico da educação superior no Brasil, no sentido de designar uma proeminência substantiva aos documentos institucionais. Com a contribuição dos instrumentos legais e reguladores da educação superior brasileira, a proposta das instituições deve se pautar na orientação de três documentos principais: o Projeto Político Institucional - PPI, o Projeto Pedagógico de Curso - PPC e, de grande relevância, o Plano de Desenvolvimento Institucional - PDI.

O arsenal documental proposto deve orientar as ações da instituição e consolidar seu posicionamento dentro das bases estruturantes de sua identidade. Tal como evidencia Souza (2007), estes documentos passam a compor a ideologia institucional, a partir de uma construção semântica da proposta acadêmica e administrativa da educação superior na instituição. A partir da utilização do arcabouço documental, a instituição pode suprimir suas 


\section{A CONTRIBUIÇÃO DO PDI NAS ATIVIDADES DE PLANEJAMENTO E GESTÃO DAS INSTITUIÇÕES DE EDUCAÇÃO SUPERIOR \\ DOI: http://dx.doi.org/10.5007/1983-4535.2012v5n3p81}

deficiências e evitar a crise de identidade, evidenciada por Cunha (1980), consolidando, de fato, o retrato e o posicionamento institucional na perspectiva de suas atividades.

Com base nesta orientação, as contribuições de Frauches e Fagundes (2007) destacam a relevância do Projeto Político Institucional - PPI, o qual deve contribuir no sentido de consolidar as políticas institucionais, articular-se com o PDI no sentido de instituir as políticas acadêmicas e de gestão numa perspectiva sistêmica, direcionando as práticas acadêmicas e as macro diretrizes institucionais, estabelecendo, de modo sustentável, a estrutura orgânica da instituição. Este, de acordo com Souza (2007), apresenta-se como um instrumento político, teórico-metodológico e filosófico, designando a vocação institucional e suas áreas de atuação acadêmica, de modo a consolidar os objetivos institucionais. No cerne de sua construção, o PPI, assim como descreve Hékis (2004), deve propor uma ênfase significativa que evidencie a indissociabilidade entre ensino, pesquisa e extensão, consolidando uma concepção formativa e que qualifiquem as ações sociais da instituição.

Nas bases de sua concepção, que deve contar com o apoio da comunidade acadêmica, Souza (2007) destaca que o documento ainda deve conter as especificidades institucionais do ponto de vista do currículo e as práticas que evidenciam a contribuição da instituição na utilização de tecnologias da informação e formação docente. Neste caso, Brasil (2004) ainda destaca que o PPI posiciona e qualifica as ações institucionais frente à proposta de responsabilidade social, norteando as ações educacionais na perspectiva formativa, contribuindo para a formação do cidadão responsável, ético e empenhado com os compromissos sociais.

Já o Projeto Pedagógico de Curso é um documento dinâmico, que envolve a comunidade acadêmica no contexto da formação de agentes designados a promover melhorias no entorno. Ele, em sua estrutura, apresenta um retrato significativo da contribuição da instituição na construção de conhecimento, destacando, entre outros aspectos, o aporte conceitual e determinante à consecução dos objetivos institucionais. A construção do documento está amparada nas bases legais de Brasil (2006) e Brasil (2007).

O Projeto Pedagógico de Curso, em sua essência, deve materializar as intenções institucionais com a educação superior, destacando o modo pelo qual a instituição utilizar-se-á das Diretrizes Curriculares Nacionais para a consecução dos objetivos e na concretização de indicadores propostos a formação do egresso. Brasil (2006) destaca que a estrutura do Projeto, que é parte integrante da proposta de avaliação institucional sob a égide do SINAES, deve 


\section{A CONTRIBUIÇÃO DO PDI NAS ATIVIDADES DE PLANEJAMENTO E GESTÃO DAS INSTITUIÇÕES DE EDUCAÇÃO SUPERIOR \\ DOI: http://dx.doi.org/10.5007/1983-4535.2012v5n3p81}

levar em consideração os momentos nos quais a reflexão sobre a formação considera a organização didático-pedagógica, a estrutura física e o corpo docente designado a formação, dentro de uma linha do tempo proposta por Brasil (2007).

A partir destas bases, o Plano de Desenvolvimento Institucional, tal como evidenciado por Souza (2007) é Silva (2008) é o instrumento norteador das práticas gerenciais da instituição, articulando os demais projetos institucionais no sentido de construir um modelo de gestão democrático e que ampare a consolidação de seus objetivos e posicionando as atividades institucionais em um contexto temporal, já que o documento é orientado para um quinquenio. Entre outros aspectos, Brasil (2006) salienta que o documento deve contemplar o perfil institucional, uma articulação significativa com os PPI, o cronograma de implantação e desenvolvimento institucional, a organização didático pedagógica, administrativa e estrutural da instituição, as políticas de atendimento ao estudante e suas práticas de acessibilidade e o demonstrativo financeiro que aporta a consolidação das políticas direcionada aos objetivos designados no PDI.

Dentro da orientação do documento, Bertoldi (2006) destaca que o PDI institui-se como documento que sustenta o posicionamento institucional e orientando a expansão institucional no sentido de demonstrar o compromisso assumido com o Ministério da Educação e com a comunidade acadêmica. Sua construção deve acontecer de forma livre, pautada nas questões levantadas pela instituição e direcionado, tal como evidencia Silva (2008), para a constituição de indicadores devidamente vinculados às políticas descritas no PPI, instituindo como base para as reflexões sistêmicas que posicionam a instituição no âmbito estratégico.

\section{INTERAÇÕES METODOLÓGICAS}

As bases metodológicas que dão sustentação a investigação tem sua estrutura alicerçada em métodos especificamente vinculados ao contexto dos objetivos propostos. Os participantes são oriundos de dez instituições de educação superior, situadas na região sul do País, destacando-se pelo posicionamento significativo no contexto do Índice Geral de Cursos - IGC - promulgado por Brasil (2008). A escolha se a partir abordagem relativa ao IGC contínuo, salientando que os participantes possuíam o índice acima de 295, configurando o IGC quatro (4). Isso, entre outros aspectos, configura-se como sendo um fator preponderante 


\section{A CONTRIBUIÇÃO DO PDI NAS ATIVIDADES DE PLANEJAMENTO E GESTÃO DAS INSTITUIÇÕES DE EDUCAÇÃO SUPERIOR \\ DOI: http://dx.doi.org/10.5007/1983-4535.2012v5n3p81}

a qualificação das instituições, sobretudo no sentido da convalidação de sua proposta de avaliação institucional pelos órgãos reguladores da educação superior brasileira.

Nesta conjuntura, a partir das contribuições de Souza, Fialho e Otani (2007), a pesquisa faz uso dos procedimentos apresentados sob o lume de sua classificação, da técnica empregada, da natureza, da abordagem do problema, das fontes de informação e dos procedimentos técnicos.

Nos direcionamentos específicos e vinculados a classificação, a pesquisa acadêmica, de acordo com Zapelini e Zapelini (2007), determina aspectos diretamente relacionados a sistematização do conhecimento com base nos pressupostos da indissociabilidade entre ensino, pesquisa e extensão. A investigação dá suporte para a utilização de técnicas designadas a consolidar o levantamento de informações, onde destaca-se a contribuição da documentação direta tendo em vista a utilização de fontes primarias e secundárias a partir de levantamentos bibliográficos vinculados os objetivos do estudo.

Já quanto a natureza, a pesquisa é aplicada, já que conforme Zapelini e Zapelini (2007, p. 95) “ identifica a situação-problema e busca, dentre as possíveis soluções, aquela que possa ser mais adequada para o contexto específico". Em seus aspectos epistemológicos, a pesquisa não tem a pretensão de criar conhecimentos novos, mas sistematizar o existente e adaptá-lo à situação problema. Já quanto aos objetivos, a pesquisa tem seu caráter descritivo-explicativo, pois confirma-se o exposto por Hair Jr. et al (2005) e Vergara (1998), visto que a investigação tem, em seus objetivos, a intenção de mensurar características descritas, construindo hipóteses que guiam o processo e analisar um fenômeno na busca de esclarecimento, tornando-o compreensível e justificável.

No sentido da abordagem do problema, a pesquisa classifica-se como sendo qualitativa, onde colima-se o exposto por Chizzotti (2006), visto que a investigação busca extrair significados visíveis e latentes, e confirma-se a reflexão de Malhorta (2001), já que a pesquisa busca promover a melhor compreensão do contexto do problema.

Como aporte, com vias a consolidar a investigação, utilizam-se, como fontes de informação, as bases da pesquisa bibliográfica, que conforme Dencker (2000) utiliza-se de fontes teóricas para consolidar a fundamentação teórica, e da pesquisa de campo, já que é feita em um âmbito específico, na busca de elementos que permitam explicar determinado fenômeno, neste caso um aspecto inerente a educação superior, utilizando-se, para tal, entrevistas semi-estruturadas que, com base nas exposições de May (2004) permite identificar 


\section{A CONTRIBUIÇÃO DO PDI NAS ATIVIDADES DE PLANEJAMENTO E GESTÃO DAS INSTITUIÇÕES DE EDUCAÇÃO SUPERIOR \\ DOI: http://dx.doi.org/10.5007/1983-4535.2012v5n3p81}

uma visão geral do entrevistado sobre determinado assunto, utilizando-se um roteiro que permita, entre outros aspectos, obter a contribuição do entrevistado.

Por fim, quanto aos procedimentos técnicos, a pesquisa classifica-se como sendo uma pesquisa participante, já que com base em Souza, Fialho e Otani (2007), permite a interação entre o pesquisador, os pesquisados e componentes das situações ou fenômenos investigados, tendo, também, as contribuições da pesquisa-ação, ensejando a participação ativa do pesquisador, buscando elucidar aspectos inerentes à problemática elencada.

\section{RETRATO ESTRUTURAL DA EDUCAÇÃO SUPERIOR BRASILEIRA}

O Instituto Nacional de Estudos e Pesquisas Educacionais Anísio Teixeira (INEP) é uma autarquia federal vinculada ao Ministério da Educação (MEC). Seu objetivo é promover pesquisas e avaliações, nos níveis existentes, do Sistema Educacional Brasileiro. Especificamente no âmbito da educação superior, o qual fornece dados relevantes às instituições brasileiras e ao seu sistema de planejamento institucional. E conforme o INEP, (2011), 2314 Instituições de Ensino Superior participaram do Censo da Educação Superior 2011, o que representou um aumento de 62 instituições em relação ao ano anterior.

A pesquisa apresenta também dados relacionados à quantidade de instituições de ensino superior, por categoria e subcategoria administrativa. A Tabela 1 - Número de Instituições por Organização Acadêmica - demonstra a divisão das 2.314 IES por organização acadêmica, em: Universidades; Centros Universitários; Faculdades Integradas; Faculdades, Escolas e Institutos e Centros de Educação Tecnológica.

Tabela 1 Número de Instituições por Organização Acadêmica

\begin{tabular}{c|c}
\hline & Universidades: 186 (8,3\%) \\
\cline { 2 - 2 } Instituições de Ensino & Centros Universitários: $127(5,4 \%)$ \\
\cline { 2 - 2 } Superior (2009): & Faculdades, Escolas e Institutos: 1.966 (84,9\%) \\
\cline { 2 - 2 } $2.314(100 \%)$ & Institutos Federais e Centros Federais de Educação \\
& Tecnológica: 35 $(1,5 \%)$ \\
\hline
\end{tabular}

Fonte: INEP 2011

Ainda com base na Tabela 1, destaca-se que a quantidade de universidades no Brasil (ano-base 2009) é de 186, independente de serem públicas ou privadas; e ainda, a maior quantidade, por organização acadêmica, fica com as Faculdades, Escolas e Institutos de ensino Superior com: 1.966 , portanto, com $84,9 \%$ de participação no total. 


\section{A CONTRIBUIÇÃO DO PDI NAS ATIVIDADES DE PLANEJAMENTO E GESTÃO DAS INSTITUIÇÕES DE EDUCAÇÃO SUPERIOR \\ DOI: http://dx.doi.org/10.5007/1983-4535.2012v5n3p81}

A Tabela 2 - Número de Instituições por Categoria e Subcategoria Administrativa demonstra, ainda com o INEP (2011), que, por categoria administrativa, dentre as 2.314 instituições de ensino superior, 245 (10,5\%) são públicas e 2.069 (89,4\%) são privadas. Por subcategoria administrativa é entendida a subdivisão entre as Instituições Públicas em: Federais; Estaduais; Municipais, e entre as Instituições Privadas: Particulares; Comunitárias; Confessionais ou Filantrópicas.

Corroboram-se o fato de se observar às peculiaridades das instituições ao se criarem modelos de gestão, já que os diversos modelos organizacionais aplicados ao ensino superior requerem a observância da identidade da instituição, seus processos, cursos oferecidos e objetivos determinados em seu Plano de Desenvolvimento Institucional (PDI). E em função desta diferenciação, torna-se imprescindível o desenvolvimento de práticas de gestão baseadas na identidade e na atuação de mercado da IES, principalmente as que atam no âmbito privado, que, conforme Garcia (2006) carece de modelos próprios de gestão aplicados.

Tabela 2 Número de Instituições por Categoria e Subcategoria Administrativa

\begin{tabular}{c|c|c}
\hline \multirow{3}{*}{$\begin{array}{c}\text { Instituições de Ensino } \\
\text { Superior }(2009):\end{array}$} & Públicas: & Federais: $94(38,3 \%)$ \\
\cline { 3 - 3 } $2.314(100 \%)$ & Privadas: & Estaduais: $84(34,2 \%)$ \\
\cline { 2 - 3 } & $2069(89,4 \%)$ & Municipais: $67(27,3 \%)$ \\
\cline { 3 - 3 } & $\begin{array}{c}\text { Comunitárias, Confessionais ou } \\
\text { Filantrópicas: } 290(13,8 \%)\end{array}$ \\
\hline
\end{tabular}

Fonte: INEP (2011).

Ainda de acordo com os dados do INEP (2011), uma terceira abordagem pode ser extraída, a subdivisão por organização acadêmica. A Tabela 3 - Número de Instituições Públicas e Privadas por Organização Acadêmica - faz esta análise. Existem, portanto, 100 universidades públicas no Brasil dentre as 245 instituições de ensino superior públicas. “Outras organizações acadêmicas" são concernentes aos Centros Universitários; Faculdades Integradas; Faculdades, Escolas e Institutos e Centros de Educação Tecnológica.

Desse modo, na tabela 3 pode-se observar os dados já descritos.

Tabela 3 Número de Instituições Públicas e Privadas por Organização Acadêmica

\begin{tabular}{|c|c|c|}
\hline \multirow{4}{*}{$\begin{array}{l}\text { Instituições de Ensino } \\
\text { Superior (2009): } \\
2.314(100 \%)\end{array}$} & \multirow[b]{2}{*}{$\begin{array}{l}\text { Públicas: } \\
245(10,5 \%)\end{array}$} & Universidades: $100(40,8 \%)$ \\
\hline & & $\begin{array}{l}\text { Outras organizações acadêmicas: } 145 \\
(59,2 \%)\end{array}$ \\
\hline & \multirow[b]{2}{*}{$\begin{array}{c}\text { Privadas: } \\
2069(89,4 \%)\end{array}$} & Universidades: $86(4,4 \%)$ \\
\hline & & $\begin{array}{c}\text { Outras organizações acadêmicas: } 1.983 \\
(96,6 \%)\end{array}$ \\
\hline
\end{tabular}

Fonte: INEP (2011). 


\section{A CONTRIBUIÇÃO DO PDI NAS ATIVIDADES DE PLANEJAMENTO E GESTÃO DAS INSTITUIÇÕES DE EDUCAÇÃO SUPERIOR \\ DOI: http://dx.doi.org/10.5007/1983-4535.2012v5n3p81}

Com a análise das universidades públicas, a partir do fato de se levantar a quantidade delas existentes por unidade federativa, conforme demonstra a Tabela 4 - Número de Universidades Públicas por Unidade da Federação. Assim, sabe-se que existem 55 universidades federais no Brasil.

A partir da Tabela 4, verifica-se que as 55 universidades federais representam 55\% das universidades públicas brasileiras. E ainda, considerando-se as Tabelas 2, 3 e 4, outros indicadores podem ser obtidos: as 55 universidades federais representam 22,4\% das 245 instituições de ensino superior públicas; e 2,3\% entre as 2.314 instituições de ensino superior pesquisadas pelo INEP.

O Censo da Educação Superior, por INEP (2011), revela outros indicadores, como a quantidade de instituições de ensino superior por região brasileira. Desta maneira, a divisão por região nacional das 2.314 instituições de ensino superior é: região Norte: 147 (6,3\%); região Centro-Oeste: 243 (10,5\%); região Sul: 386 (16,6\%); região Nordeste: 448 (19,3\%) e região Sudeste: $1.090(47,1)$.

Tabela 4 Número de Universidades Públicas por Unidade da Federação

\begin{tabular}{c|c}
\hline Universidades Públicas (2009): & Federais: $55(55 \%)$ \\
\cline { 2 - 2 } $100(100 \%)$ & Estaduais: $38(38 \%)$ \\
\cline { 2 - 2 } & Municipais: $7(6 \%)$ \\
\hline
\end{tabular}

Fonte: INEP (2011).

Demais indicadores do Censo da Educação Superior, coletados pelo INEP (2011), podem ser citados: existem 27.827 cursos de graduação presencial; 5.115 .896 matrículas efetivadas na graduação presencial; e o curso com a maior quantidade de alunos matriculados na graduação presencial é da Administração, com 870.536 (17,1\% do total de matrículas); e a modalidade de ensino "educação a distância" teve 838.125 alunos matriculados.

Percebe-se que no âmbito privado, em função do número de matriculas, a concorrência entre as instituições é acirrada em todos os âmbitos de atuação de seus programas de graduação. O que pode fornecer indicadores para uma gestão eficaz em função dos objetivos da instituição e de sua mantenedora a partir dos aspectos estruturais, pedagógicos, metodológicos e operacionais apresentados pela instituição.

Dentre as 5.115.896 matrículas efetivadas na graduação presencial, o Censo aponta que 53,1\% (2.715.720) foram das Universidades; as Faculdades Integradas obtiveram 31,9\% (1.634.115) e os Centros Universitários realizaram (13,9\%), 711.328 matrículas. Já os 


\section{A CONTRIBUIÇÃO DO PDI NAS ATIVIDADES DE PLANEJAMENTO E GESTÃO DAS INSTITUIÇÕES DE EDUCAÇÃO SUPERIOR \\ DOI: http://dx.doi.org/10.5007/1983-4535.2012v5n3p81}

Institutos Federais e os Centros Federais de Educação Tecnológica matricularam 54.733, ou seja $1,06 \%$ do total de matriculas.

A Tabela 5 - Quantidade de Matrículas por Categoria e Subcategoria Administrativa confirma os dados do INEP (2011) já que das 5.115.896 matrículas na graduação presencial de 2009, apenas 752.847 foram efetivadas pelas instituições públicas federais.

Tabela 5 Quantidade de Matrículas por Categoria e Subcategoria Administrativa

\begin{tabular}{c|c|c}
\hline & Pública: & Federal: $752.847(55,7 \%)$ \\
\cline { 3 - 3 } Matrículas na Graduação & 1.351 .168 & Estadual: $480.145(35,5 \%)$ \\
\cline { 3 - 3 } Presencial (2009): & $(26,4 \%)$ & Municipal: $118.176(8,7 \%)$ \\
\cline { 2 - 3 } $5.115 .896(100 \%)$ & Privada: & Particular: 2.899.763(77,1) \\
& 3.764 .728 & Comunitárias, Confessionais \\
& $(74,6 \%)$ & Filantrópicas: 864.965 (22,9) \\
\hline
\end{tabular}

Fonte: INEP (2011).

No bojo deste desenvolvimento, as instituições de ensino superior privadas, em 2009, representaram $74,6 \%$ do total das matriculas no ensino superior, respondem por 3.764.728 das matrículas brasileiras, ou seja, tais instituições preconizam modelos de gestão que potencialize suas ações de mercado. Além deste aspecto, deve-se considerar que os números referentes a educação superior no Brasil permitem, entre outros aspectos, direcionar ações que consolidem a atividade das instituições publicas e privadas, sobretudo por meio da identificação de práticas organizacionais e institucionais que determinam a eficácia e o posicionamento de cada instituição.

\subsection{RETRATO DA ATIVIDADE DO SEGMENTO PRIVADO: ATENÇÃO À CONTRITUIÇÃO ESTRATÉGICA DO PDI}

Em sua concepção, o Plano de Desenvolvimento Institucional, tal como evidenciado por Frauches e Fagundes (2007), coaduna-se no sentido de posicionar a missão institucional, instituindo, a partir da articulação com o Projeto Pedagógico Institucional - PPI, constituindo políticas que direcionam projetos e planos aplicados ao contexto da instituição. Na sua estrutura, o aporte estratégico se dá no sentido apresenta a partir da possibilidade da designação de objetivos e metas, os quais, na contribuição de Souza (2007), estão diretamente relacionados com a consolidação dos objetivos institucionais.

Nas bases propostas por Brasil (2004), o PDI deve identificar a epistemologia da instituição, salientando, do ponto de vista filosófico, os direcionamentos de trabalho bem 


\section{A CONTRIBUIÇÃO DO PDI NAS ATIVIDADES DE PLANEJAMENTO E GESTÃO DAS INSTITUIÇÕES DE EDUCAÇÃO SUPERIOR \\ DOI: http://dx.doi.org/10.5007/1983-4535.2012v5n3p81}

como a missão a qual a organização se propõe, além das diretrizes que orientam as atividades institucionais e acadêmicas que a IES se propõe a desenvolver num interregno de tempo. $\mathrm{Na}$ linha designada por Brasil (2001), consolidada por Brasil (2006), o documento deve estar alinhado a legislação vigente, contudo sua construção poderá se fazer de forma livre, permitindo que a instituição exercite sua capacidade construtivista e sua eloqüência institucional, consolidando os eixos formativos determinados pela estrutura curricular de seus programas de graduação.

Entre outros aspectos, o PDI se relaciona, sobretudo com os procedimentos regulatórios da educação superior brasileira, sendo que os principais são o credenciamento e o recredenciamento institucional, também servindo de base para as demais avaliações de curso que ocorrem sob a égide de Brasil (2004). O documento tem um caráter dinâmico que requer uma compreensão significativa do cenário no qual a instituição se insere, promovendo um exercício prospectivo do ponto de vista da demanda e da oferta de toda a instituição.

Dentro de seu contexto estrutural, tal como evidenciado por Brasil (2006), o documento deve apresentar um cronograma da implantação das metas, observando, entre diversos aspectos relevantes, a articulação entre as ações institucionais e a proposta de qualidade determinada por SINAES (2009). É nesta conjectura que se destaca uma das funções principais do documento que é a de direcionar os esforços da avaliação institucional, no contexto de todos os procedimentos relacionados a construção da identidade da instituição de educação superior.

A construção do documento, sobretudo ao passo de se considerar a instituição de educação superior como sendo uma organização com objetivos definidos e delineados de modo convergente, deve se fazer nas bases estruturantes de Dias (1989), consolidando os desafios apresentados por Marquesi (2008) às instituições de educação superior, os quais estão diretamente relacionados com a complexidade da era do conhecimento que afeta de modo direto as organizações contemporâneas.

O PDI, na linha conceitual de Veiga (2004), deve seguir uma linha inovadora, respeitando seu aspecto temporal, permitindo que a instituição enfrente de modo coerente os desafios a partir de uma nova realidade em suas práticas gerenciais, destacando um novo pensamento organizacional e acadêmico em sua estrutura. Nisso, coadunam-se as questões evidenciadas por Brasil (2006) que denotam a relação intima entre o PDI e a prática gerencial, destacando o posicionamento gerencial da instituição que se relaciona com os resultados 


\section{A CONTRIBUIÇÃO DO PDI NAS ATIVIDADES DE PLANEJAMENTO E GESTÃO DAS INSTITUIÇÕES DE EDUCAÇÃO SUPERIOR \\ DOI: http://dx.doi.org/10.5007/1983-4535.2012v5n3p81}

ensejados e atingidos, onde a avaliação nas bases de Brasil (2004) consolida, de fato, a estrutura do documento.

No ponto de vista dos entrevistados, corroborando os expostos por Souza (2007), o PDI deve promover um exercício gerencial a instituição, permitindo a construção de um modelo gerencial compatível com seus recursos, designando a construção de objetivos e promovendo um diagnóstico da realidade institucional. Tal como evidenciado por Garcia (2006), a consolidação deste processo leva em consideração a participação democrática da comunidade acadêmica, retratando a pluralidade da instituição e sua participação na construção social. Destarte, o PDI deve apontar para uma gestão democrática, alinhado aos anseios sociais e aos pressupostos sustentáveis que caracterizam o modelo educacional previsto pelo relatório da UNESCO e pelo Tratado de Bolonha.

Na perspectiva estratégica, o documento arrola práticas de gestão e que, de acordo com Souza (2007) e Silva (2008), buscam consolidar objetivos convergentes aos diversos agentes institucionais, destacando a atividade de todos no contexto da organização acadêmica e administrativa, contextualizando a inserção institucional no cerne das tecnologias da informação e os demais aspectos que devem ser compreendidos sob a égide da gestão universitária. Por isso, confirmam-se os expostos de Frauches e Fagundes (2007), que destacam o PDI como sento um instrumento norteador do desenvolvimento da IES, onde se expressam as exigências legais e essenciais a gestão institucional, definindo um modelo a ser implantado e seguido na instituição.

Com base nestes aspectos, o PDI confirma-se como um instrumento de gestão, sobretudo ao passo da identificação dos objetivos institucionais e como apoio à construção de políticas designadas a partir da articulação com o PPI. A partir dos expostos por Souza (2007), o PDI desencadeia uma metodologia participativa na qual toda a comunidade acadêmica é a responsável por consolidar os ensejos institucionais, promovendo a maximização de recursos humanos, físicos e, até mesmo sociais, promovendo relações coesas entre a instituição e o cenário no qual ela se posiciona e fundamentando suas ações intra e interorganizacionais, destacadas por Mendes (2005), como sendo fundamentais ao modelo das instituições de educação superior. 


\section{A CONTRIBUIÇÃO DO PDI NAS ATIVIDADES DE PLANEJAMENTO E GESTÃO DAS INSTITUIÇÕES DE EDUCAÇÃO SUPERIOR \\ DOI: http://dx.doi.org/10.5007/1983-4535.2012v5n3p81}

\subsection{A AVALIAÇÃO INSTITUCIONA: A RELEVÂNCIA NA VALIDAÇÃO DA}

ATIVIDADE INSTITUCIONAL

A partir da contribuição dos pesquisados, confirmam-se os expostos destacados por Segenreich (2005) e que destacam a aderência entre o PDI e o processo de avaliação institucional. As contribuições destacam a possibilidade de introduzir a instituição em uma concepção formativa, tal como elencada nas premissas da CONAES por intermédio de Brasil (2004), configurando o Plano de Desenvolvimento Institucional como instrumento norteador das premissas de qualidade da instituição.

Centrado nos aspectos que configuram a qualidade da educação superior, o PDI passa a ter um aspecto balizador das ações institucionais, identificando a posicionando os aspectos que confirmam o compromisso institucional com a educação superior e os pressupostos de qualidade da instituição que se funda em objetivos factíveis. Desse modo, o PDI passa a identificar a relação da instituição com a sociedade, por intermédio de sua missão, partindo de pressupostos que elucidam a contribuição da instituição com a formação intelectual da sociedade.

Com base nestes fundamentos, o PDI, tal como evidenciado por Segenreich (2005) passa a modificar pessoas a partir do resgate de perspectivas históricas e que determinam a relação dos valores institucionais com os processos gerenciais da instituição. Por fundamento, estes aspectos devem possuir uma aderência significativa, desencadeando o que Brasil (2010) considera um referencial mínimo de qualidade para a atividade da instituição. Destaca-se que, ao contribuir com a avaliação institucional, o PDI passa a promover possibilidades de construção de estudos sistemáticos no âmbito da instituição, determinando disposições democráticas e burocráticas que evidenciam a qualidade institucional.

Outro aspecto a ser destacado é o fato de que o PDI corrobora a qualidade da instituição, contribuindo para a eficácia dos procedimentos avaliativos, no momento em que delimita objetivos dentro do contexto de atividade da instituição, identificando aspectos, procedimentos e processos alinhados com o perfil institucional. Confirma-se então o exposto por Tachizawa e Andrade (2006), que destacam a necessidade de um conhecimento significativo, por parte dos gestores institucionais, das práticas que posicionam a instituição em um ambiente de alta competitividade, tal como o da educação superior brasileira.

Com base nestes pressupostos, o PDI passa a integrar o pensamento e a ação institucional, consolidando a identidade da instituição com base em processos gerenciais bem 


\section{A CONTRIBUIÇÃO DO PDI NAS ATIVIDADES DE PLANEJAMENTO E GESTÃO DAS INSTITUIÇÕES DE EDUCAÇÃO SUPERIOR \\ DOI: http://dx.doi.org/10.5007/1983-4535.2012v5n3p81}

delimitados, determinando a percepção da qualidade do fazer acadêmico a partir da relação direta com seus principais stakeholders. Desse modo, tal como evidenciado por SINAES (2009), a qualidade da instituição passa a estar determinantemente ligada ao cumprimento de sua missão e de seus objetivos, fatores que tem uma relação significativa com a avaliação institucional e, sobretudo, com seu contexto técnico-gerencial.

Destarte, com base nos pressupostos norteadores da educação superior brasileira, o Plano de Desenvolvimento Institucional passa a se consolidar como fator preponderante na consolidação dos princípios do SINAES no contexto da atividade de cada instituição. Neste sentido, a documento elenca aspectos que determinam as ações institucionais aderentes a responsabilidade social com a qualidade da educação superior, ao reconhecimento e, por conseguinte, posicionamento de uma identidade substantiva e aderente a missão da instituição, e com a globalidade, por meio da promoção de indicadores que mantém uma relação orgânica com a instituição, corroborando a avaliação como uma política institucional declarada em seus projetos institucionais.

\section{CONSIDERAÇÕES FINAIS}

Por fundamento, o Plano de Desenvolvimento Institucional emerge de pressupostos técnico-conceituais que determinam a eficácia das atividades de uma instituição de educação superior. Desse modo, o PDI se configura como um documento estratégico da instituição, o qual é elaborado por um período pré-determinado e que tem em seu bojo estrutural a função de consolidar a fillosofia da instituição. Dentro de suas principais funções, o documento elenca a missão, as diretrizes de trabalho da instituição, além de consolidar a estrutura central das atividades acadêmicas desenvolvidas pela entidade, determinando políticas que coadunam-se com os objetivos centrais da instituição e que se validam no processo de avaliação institucional.

A pesquisa corrobora o fundamentado no referencial teórico, já que as investigações consolidam a importância do PDI na gestão institucional, destacando a relevância do bojo estrutural do documento, no sentido de posicionar as habilidades institucionais frente aos ensejos da conjuntura da educação superior. Na égide semântica, o PDI passa a se configurar como o instrumento central da filosofia gerencial da instituição, consolidando objetivos e metas que convergem para a consecução de objetivos comuns das instituições e dos órgãos reguladores da educação superior brasileira. 


\section{A CONTRIBUIÇÃO DO PDI NAS ATIVIDADES DE PLANEJAMENTO E GESTÃO DAS INSTITUIÇÕES DE EDUCAÇÃO SUPERIOR \\ DOI: http://dx.doi.org/10.5007/1983-4535.2012v5n3p81}

A partir da orientação proporcionada à avaliação da instituição, desencadeando pontos que qualificam as ações institucionais, os aspectos que confirmam a relevância do Documento na estruturação do planejamento da instituição se referem ao fato da contribuição estratégica do PDI e da colaboração substantiva no processo de avaliação institucional. Pode-se inferir que o PDI passa a orientar uma percepção significativa da conjuntura da educação superior, permitindo que as instituições se posicionem frente aos desafios apontados pelas perspectivas, consolidando uma orientação significativa ao processo de avaliação institucional com base em uma concepção formativa.

O documento se consolida como o principal referencial da avaliação externa das instituições a partir de sua articulação com as práticas gerenciais e de ensino preconizadas pelas instituições. O PDI torna-se, portanto, o principal referencial de gestão das instituições de educação superior, independente de sua categoria administrativa ou configuração acadêmica.

$\mathrm{Na}$ contribuição ao processo gerencial, o PDI passa a inserir a instituição em um ambiente estratégico, tornando a elaboração do documento um processo sistemico e dinâmico, que requer a participação de todos os membros da comunidade acadêmica. Tal como elenca Brasil (2006), o Plano de Desenvolvimento Institucional passa a explicitar os pressupostos gerenciais da instituição, introduzindo suas práticas em um âmbito do planejamento. De igual modo, o documento passa a considerar objetivos factíveis e que se relacionam com a missão da instituição, fundamentando políticas que permitam a sustentabilidade e a perenidade da instituição, confirmando seus compromissos sociais e os demais princípios de qualidade da educação superior.

Já sobre a égide do processo de avaliação institucional, o PDI passa a contribuir no sentido de promover uma compreensão significativa do escopo institucional frente as dimensões propostas pela sistemática de avaliação brasileira. O SINAES, passa então a compor a estrutura do PDI, orientando as atividades institucionais, as políticas e os objetivos centrais da instituição no sentido de buscar a qualidade ensejada nas metas propostas para o período destacado no Documento. Desse modo, entre outros aspectos, o PDI passa a se consolidar como o instrumento norteador das políticas institucionais que convergem para à eficácia dos processos de ensino e aprendizagem, consolidando uma atividade sustentável perante aos ensejos das orientações regulatórias da educação superior brasileira. 


\section{REFERÊNCIAS}

AMARAL, Nelson Cardoso. O limite na expansão da educação superior privada no Brasil, regiões e Estados. Goiás (digitalizado), 2006.

BERTOLDI, Werner José. Processo de implantação do Plano Institucional de Desenvolvimento Integrado na Universidade do Contestado/UnC. 2006.87 f. Dissertação (Mestrado em Administração) - Curso de Pós-Graduação em Administração. Universidade Federal de Santa Catarina, Florianópolis, 2006.

BRAGA, Ryon. Análise setorial do ensino superior privado no Brasil: tendências e perspectivas 2006 - 2010. São Paulo: Hoper. 2005.

BRAGA, Ryon. Cenário da Educação Superior no Brasil e em Santa Catarina.São Paulo: Hoper. 2009.

BRASIL, Congresso Nacional. Lei de diretrizes e Bases da Educação Nacional. Estabelece as diretrizes e bases para a educação nacional. Rio de Janeiro: Ed Esplanada, 1996.

BRASIL, Presidência da Republica. Decreto $\mathrm{N}^{\mathbf{0}}$ 3.860, de 9 de julho de 2001. Casa Civil: Subchefia para assuntos jurídicos: 2001.

BRASIL, Presidência da Republica. Decreto $\mathbf{N}^{\mathbf{0} 5773}$, de 9 de maio de 2006. Casa Civil: Subchefia para assuntos jurídicos: 2006.

BRASIL, Presidência da Republica. Lei $\mathbf{N}^{\mathbf{0}}$ 10.172, de 9 de janeiro de 2001. Casa Civil: Subchefia para assuntos jurídicos: 2001.

BRASIL, Presidência da Republica. Lei No 10.861, de 14 de Abril de 2004. Brasília: 2004.

BRASIL, Presidência da Republica. Lei No 10.861, de 14 de Abril de 2004. Brasília: 2004.

BRASIL, Presidência da Republica. Lei $\mathbf{N}^{\mathbf{0}}$ 9.786, de 8 de fevereiro de 1999. Casa Civil: Subchefia para assuntos jurídicos: 1999.

BRASIL. Constituição: República Federativa do Brasil, Brasília: Senado Federal, Centro Gráfico, 1988.

BRASIL. Instrumento de avaliação institucional externa. Comissão Nacional de Avaliação da Educação Superior. Instituto Nacional de Estudos e Pesquisas Educacionais Anísio Teixeira. Ministério da Educação. Brasília. 2010.

BRASIL. Portaria $\mathbf{N}^{0}$ 821, de 9 de agosto de 2009. Gabinete do Ministro da Educação. Brasília. 2009.

BRASIL. Portaria Normativa $\mathbf{N}^{\mathbf{0}} 12$, de 5 de setembro de 2008. Gabinete do Ministro da Educação. Brasília. 2008. 
BRASIL. Portaria Normativa $\mathbf{N}^{\mathbf{0}} 23$, de 01 de dezembro de 2010. Gabinete do Ministro da Educação. Brasília. 2010.

BRASIL. Portaria Normativa $\mathrm{N}^{\mathbf{0}} \mathbf{4 0}$, de 01 de dezembro de 2010. Gabinete do Ministro da Educação. Brasília. 2007.

BRASIL. Presidência da República. Decreto $\mathrm{N}^{\mathbf{0}}$ 6303, de 12 de novembro de 2007. Casa Civil: Subchefia para assuntos jurídicos: 2001.

BUARQUE, Cristovam. A Aventura da universidade. Rio de Janeiro: Paz e Terra, 1994.

TÓVOLI, Emília Maria Gaspar; SEGATTO José Antonio; NOGUEIRA, Marco Aurélio (Org.). Gestão Universitária. São Paulo: Editora UNESP, 2005.

CHIZZOTTI, Antonio. Pesquisa qualitativa em ciências humanas e sociais. Petrópolis: Vozes, 2006.

CUNHA, Luiz. Antonio. A universidade temporã: o ensino superior da colônia à era de Vargas. Rio de Janeiro: Francisco Alves, 1980.

DENCKER, Ada. de F. M. Métodos e técnicas de pesquisa em turismo. 4. ed. São Paulo: Futura, 2000.

DIAS, Francisco. C. Construção do sistema universitário do Brasil: memória histórica do Conselho de Reitores das Universidades Brasileiras, CRUB, 1989.

ESTEVES, Paulo.Cesar.L. Fatores determinantes de mudanças na estrutura competitiva do sistema de ensino superior de Santa Catarina. Tese. 154f. (Tese de Doutorado). Programa de Pós-Graduação em Engenharia e Gestão do Conhecimento. Universidade Federal de Santa Catarina, 2007.

ESTRADA, Rolando Juan Soliz. Os Rumos do planejamento estratégico na universidade pública: um estudo de caso na Universidade Federal de Santa Maria. Tese. 206f. (Tese de Doutorado). Programa de Pós-Graduação em Engenharia da Produção. Florianópolis: 2000.

FRAUCHES, Celso.C.; FAGUNDES, Gustavo. M, LDB Anotada e Comentada e Reflexões sobre a Educação Superior. 2 ed. Brasília: 2007.

GARCIA, Mauricio. Gestão profissional em instituições privadas de educação superior Um Guia de sobrevivência para mantenedores, acionistas, reitores, pró-reitores, diretores, coordenadores, gerentes e outros gestores institucionais. 1 ed. São Paulo: Hoper 2006.

HAIR JR., Joseph et al. Fundamentos de métodos de pesquisa em Administração. Porto Alegre: Bookman, 2005.

HÉKIS, Hélio. R. Balanced scorecard: proposta de indicadores para monitorar e avaliar projetos pedagógicos dos cursos de graduação: o caso da Faculdade Estácio de Sá de 
Santa Catarina. Tese (Doutorado). 221fl. - Programa de Pós- Graduação em Engenharia da Produção. Universidade Federal de Santa Catarina. 2004.

INEP. Portaria $\mathbf{N}^{\mathbf{0}} 300$, de 30 de janeiro de 2006. Publicada no Diário Oficial da União $\mathrm{N}^{\mathrm{o}}$ 22, Seção I de 31 de janeiro de 2006.

INEP/MEC. Censo da Educação Superior 2009. Brasília: Ministério da Educação, 2011.

KLEBER Klaus; TREVISAN Leonardo.(Org). Produzindo capital humano. O papel do ensino superior privado como agente econômico e social. São Paulo, Cultura: 2010.

LERNER, Alexandra. L. A Strategic Planning: Primer for Higher Education. Califórnia State University. Califórnia: College of Business Administration and Economics, 1999. Disponível em http://www.des.calstate.edu/strategic.html Acessado em março de 2004.

MACHADO, Luis. E. Gestão Estratégica para instituições de ensino superior privadas. 1 ed. - São Paul: FGV Editora 2008.

MALHOTRA, Naresh. K. Marketing Research: An Applied Orientation. Upper Saddle River, $3^{\mathrm{a}}$ ed.: Prentice Hall, 2001.

MARCELINO, Gileno. F.(Org,); Gestão Estratégica de Universidade. 1 ed. Brasília: Editora UNB, 2004.

MARQUESI, Sonia.C. O papel do dirigente universitário no envolvimento da comunidade acadêmica para a construção do plano de desenvolvimento institucional. Monografia apresentada no IGLU, XIX Curso de Especialização em Administração Universitária, Porto Alegre, 2002.

MAY, Tim. Pesquisa social: questões, métodos e processos. 3. ed. Porto Alegre: Artmed, 2004.

MORA, José-Ginés; HORTALE, Virginia. A. Tendências das reformas da educação superior no contexto do processo de Bolonha. Educação e Sociedade, Campinas, v. 25, n. 88, p. $937-$ 960, out. 2004. Disponível em: <http://www.cedes.unicamp.br>. Acesso em: 06 fev. 2007.

PORTER, Michael E. Vantagem Competitiva: Criando e Sustentando um Desempenho superior. Rio de Janeiro: Editora Campus, 1990.

RIZZO, Claudia. Gestão estratégica do aluno/cliente nas instituições de ensino superior privadas: um estudo de caso. Tese. 123f. (Tese de Doutorado). Programa de Pós-Graduação em Administração da Universidade de São Paulo. USP. 2009.

SALLES, Paulo Eduardo Marcondes. $O$ futuro do planejamento estratégico nas IES. In: GARCIA, Mauricio. et al. Gestão Profissional em Instituições Privadas de Ensino Superior: um "guia de 128 sobrevivência" para mantenedores, acionistas, reitores, pró-reitores, diretores, coordenadores, gerentes e outros gestores institucionais. Brasil: Hoper, 2006. 
SEGENREICH, Stella.Cecília.D. O PDI como referente para avaliação de instituições de educação superior: lições de uma experiência. Ensaio: avaliação, políticas públicas e educação. Rio de Janeiro, v.13, n 47, p, 149-168. Abr-Jun.2005.

SENGE Peter. A Quinta disciplina: arte, teoria e prática de organização de aprendizagem. 9a ed. Tradução por Regina Amarante. São Paulo: Best Seller, 1990.

SILVA, Renato. Balanced Scorecard - BSC - Gestão do Ensino Superior - Gestão Profissionalizada e Qualidade de Ensino para Instituições de Ensino Superior Privado. Jurua Curitiba - 2008 .

SINAES. Sistema nacional de avaliação da educação superior: da concepção à regulamentação. 5ed., revisada e ampliada - Brasília: INEP, 2009.

SOUZA, Antonio. C.; FIALHO, Francisco. A. P.; OTANI, Nilo. TCC Métodos e Ténicas. $1^{\text {a }}$ Ed. Florianópolis: Visualbooks, 2007.

SOUZA, José. Carlos.V.. Gestão universitária em instituições particulares: Os documentos institucionais como indicadores do modelo de gestão. Tese. $208 \mathrm{f}$. (Tese de Doutorado)..- Programa de Pós-Graduação em Educação e currículo da Pontifícia Universidade Católica de São Paulo. 2007.

STEINER, João.E.; MALNIC, Gerard (Orgs). Ensino Superior - Conceito e Dinâmica. $1^{\text {a }}$ Ed. São Paulo: EdUSP: 2006.

TACHIZAWA, Takeshi; ANDRADE, Rui.Otávio.B. Gestão de instituições de ensino. 4ed. rev. e ampl. Editora FGV. Rio de Janeiro. 2006.

VEIGA, Ilma. Passos.A. Educação Básica e Educação Superior: projeto pedagógico. Campinas: 2004.

VERGARA, Silvia.C. Métodos de pesquisa em administração. São Paulo: Atlas, 2005.

VOOS, Jordelina Beatriz Anacleto. O processo de Avaliação Institucional e a adaptação estratégica na Universidade da Região de Joinville - UNIVILLE. 2004. 216 f. (Tese (Doutorado). Programa de Pós-Graduação em Engenharia da Produção da Universidade Federal de Santa Catarina, Florianópolis: 2004.

ZAPELINI, Marcelo.B; ZAPELINI, Silvia.M.K.C. Metodologia científica e da pesquisa para o curso de Administração. Apostila do curso de Administração. Faculdade Energia de Administração e Negócios, 2007. 